\title{
An analysis of the OPEC and Non-OPEC position in the World Oil Market: A fractionally integrated approach
}

\author{
Luis, A. Gil- Alana \\ Professor of Economics, economic Department, University of Navarra, Spain. \\ Yadollah Dadgar \\ Professor of Economics, Economics Department, Beheshty University, Iran. \\ Rouhollah Nazari \\ Ph.D Candidate of Economics, Ferdowsi University, Iran.
}

\begin{abstract}
This paper deals with the analysis of the world, OPEC and non-OPEC oil production by testing the degree of persistence of the series throughout fractional integration. The analysis is relevant in the sense that it allows us to determine if shocks in the series have permanent or transitory effects. The results indicate evidence of mean reversion in the three series, especially for the world and OPEC production. We also notice evidence of multiple breaks though the degree of persistence seems to be relatively stable across the subsamples, with most of the values in the range $[0.5,1)$ implying non-stationary and mean reverting behavior.
\end{abstract}

Keywords: OPEC; Non-OPEC; Oil Production; fractional integration

JEL Classification: C22, Q43.

Corresponding author: Prof. Luis A. Gil-Alana

University of Navarra

Faculty of Economics and ICS-NDID

31009 Pamplona

Spain

Email: alana@unav.es

*: Prof. Luis A. Gil-Alana gratefully acknowledges financial support from the Ministerio de Ciencia, Innovación y Universidades (ECO2017-85503-R). 


\section{Introduction}

The Organization of Petroleum Exporting Countries (OPEC) is a permanent intergovernmental organization, created on September 14, 1960 by its five founding members (Saudi Arabia, Kuwait, Iran, Iraq and Venezuela). Nowadays, it consists of fifteen oil producing and exporting countries spread across three continents; Latin America, Middle East and Africa. OPEC's objective is to coordinate and unify petroleum policies among member countries, in order to secure reasonable and stable prices for petroleum producers; a desired supply of petroleum to consuming nations; and an admissible return on capital to those investing in the industry. Studying the behavior of major oil producers (OPEC and non-OPEC) has always been one of the issues facing economic experts. The emergence of OPEC as a major actor in the oil market has led many studies to be conducted on the behavior of OPEC and its member countries.

Based on OPEC's Annual Statistical Bulletin 2018, the total population of OPEC members ${ }^{1}$ (14 countries with the overall area amounting to 12,158 thousand square kilometers and annual per capita GDP reaching 6,220 dollars) was 495.5 million at the end of 2017 (OPEC, 2018). The relationship between OPEC and non-OPEC countries is important because it can result in stability of the oil market and control of crude oil price. Until the end of the 1980s, there were no interactions between the two groups. At that time, it was thought that the demand for crude oil was sufficiently strong even after four- fold price rise in 1973-1974 period. Another sharp increase in oil price in 1979-1980 influenced demand during the first-half of 1980s. At same time, supply of non-OPEC countries increased, and OPEC found out that it would not be able to ignore non-OPEC production in maintaining the stability the oil market. Production of OPEC had a sharp descending

\footnotetext{
${ }^{1}$ The Congo became OPEC's fifteenth member in 2018. Given that OPEC's annual statistics at 2018 have been considered based on the statistics for member countries by the end of 2017, thus the statistics of this country is not included.
} 
trend from 1980 to 1985 . In the meantime, Saudi Arabia, which had played the role of a regulator in the first half of the 1980s, withdrew from that role in the second half of the 1980s.

In the early 1990s, Iraq regime invaded Kuwait aiming to control its oil resources. It fired the oil wells of this country and caused oil prices to rise. The decline in US oil demand and the increase in OPEC members' quotas caused the surplus of oil supply till 1995. In 1997 and 1998, the South East Asian crisis slowed down the oil consumption of these countries which caused a fall in prices. The slowdown in US economic growth at 2001 and the increase in non-OPEC production led to a decline in oil prices, which reduced quotas 3.5 million barrels per day in early September 2001. After September 11, 2011, oil prices started falling sharply. However, due to the political conditions of its members, OPEC reduced its quotas and as a result its production capacity decreased to 1.5 million barrels per day in January 2002. Factors such as strikes in Venezuela at the beginning of 2003, global economic growth, high gas prices, China's rising demand, and US military attacks to Iraq were the main reasons for rising oil prices in 2003. But the rise in oil prices during 2004 and June 2008 was resulted from the economic growth of China and India, the rising demand for oil by the countries, the devaluation of dollar, the unrest and riots in Nigeria, and the Iran's nuclear disputes with Western countries. The disclosure of the effects of global financial crisis (beginning in late 2007) caused a drop of oil prices from July 2008 to December 2008. From 2009 to 2018, there has been some fluctuations in oil price which due to the sanctions imposed by America against Iran in 2011; the Arab Spring and internal conflicts in the Middle East countries including Libya and Iraq; western countries' nuclear debate with Iran; Saudi Arabia's military attacks against Yemen; increased production of shale oil (light tight oil) in the United States; an agreement to reduce the oil production of non-OPEC and OPEC countries on December 10, 2016; America's withdrawal from the nuclear deal with Iran and tightening sanctions against Iran in 2018. The behavior of World, OPEC and non-OPEC oil production over 1973:01 to 2018:04 is shown in Figure 1. 


\section{Figure 1: OPEC, Non-OPEC and World oil production}

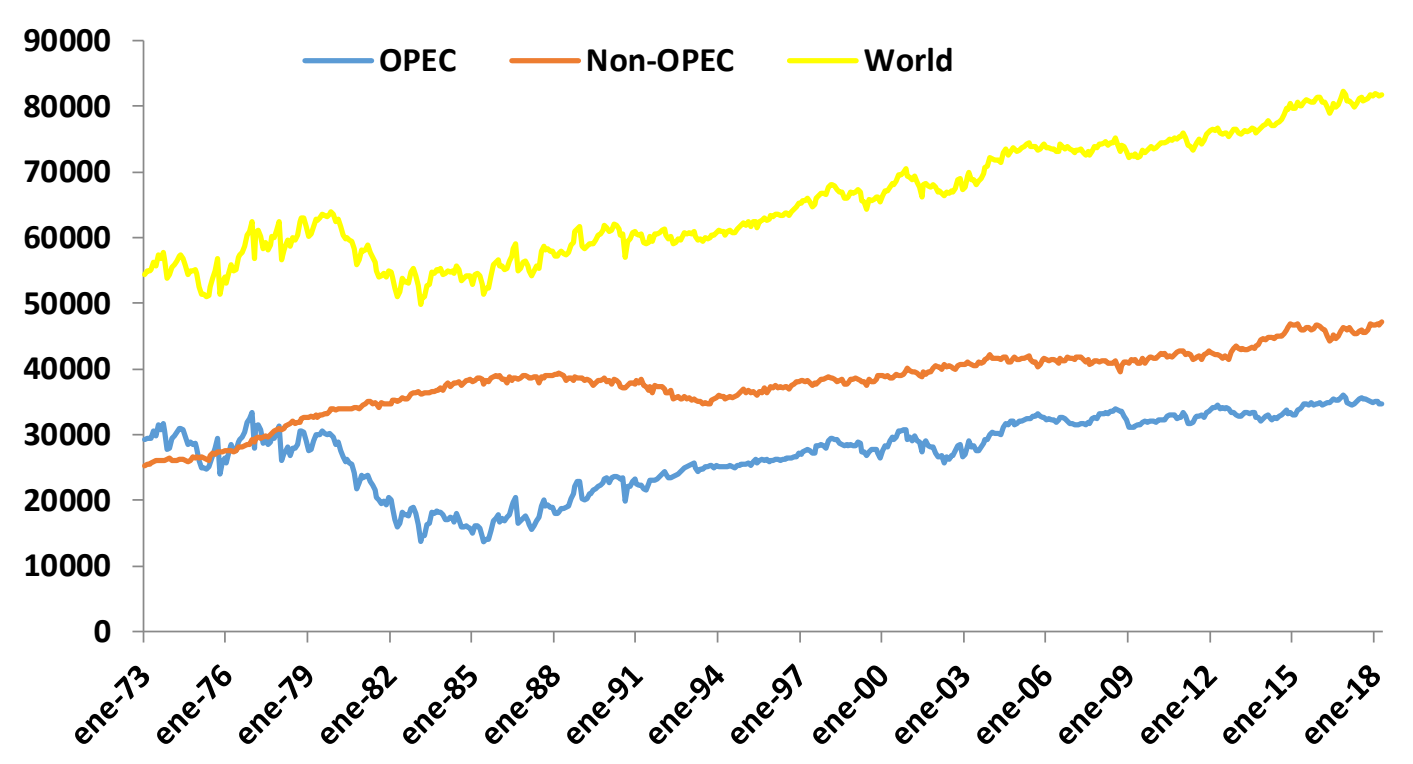

The review of the non-OPEC production time series from 1973:01 to 2018:04 indicates an increase in their share in world crude oil markets. The share of Non-OPEC rose from $46.4 \%$ from January 1973 to $57.6 \%$ in August 2018. Increasing the share of non-OPEC crude oil was due to the increased global demand and the policy of maintaining price levels in the market. Non-OPEC countries are always struggling to increase the share of oil markets by increasing their operational capability, discovering new reserves, reducing operational costs, and using the maximum production capacity. If the non-OPEC share of the global supply of oil continues to increase in the global market and the OPEC share does not, the effective control of the market will be available to non-OPEC countries and OPEC cannot improve its position. This is not, however, the foreseen case and the dependence on of world market to OPEC product will increase in 2019 and afterwards due to a decrease in non-OPEC productions.

Although about 57.6 percent of the world's crude oil production occurs in non-OPEC countries, the crude oil production in these countries is facing with some problems. A curtail 
problem is that many wells of non-OPEC producers are rapidly evacuating. Also, in some nonOPEC areas, crude oil production is not economical due to high costs, and low production/Reserves ratio. Seven producers from the world's fifteen largest producers, including Russia, the United States, China, Mexico, Canada, Norway and Brazil, are among the non-OPEC countries, and thus play an important role in determining the price of crude oil. Other non-OPEC crude oil producing countries are, however, developing countries, which due to population growth, consume a major part of their crude oil production domestically. As a result, at the time of the fluctuation of crude oil prices, these countries act as a consumer and not active exporters. The economies of OPEC countries are mainly dependent on crude oil revenues. A large part of the foreign exchange earnings of OPEC countries comes from exporting crude oil, so that the sharp fluctuations in crude oil price will transform the economic conditions of these countries remarkably. For example, in times of falling price, these countries may use the policy of increasing crude oil supply to finance budget deficits rather than applying a policy of reducing crude oil supply to raise prices. A major part of investments in OPEC countries is made by the public sector, which also have a high dependence on crude oil revenue volatility. That is why the increase in crude oil prices, followed by the increase in oil revenues, coincided with an overdue increase in the number of government projects and development projects, and the fall in the price of crude oil would put the projects at a standstill. The share of OPEC and non-OPEC in the world oil market is shown in Figure 2. 


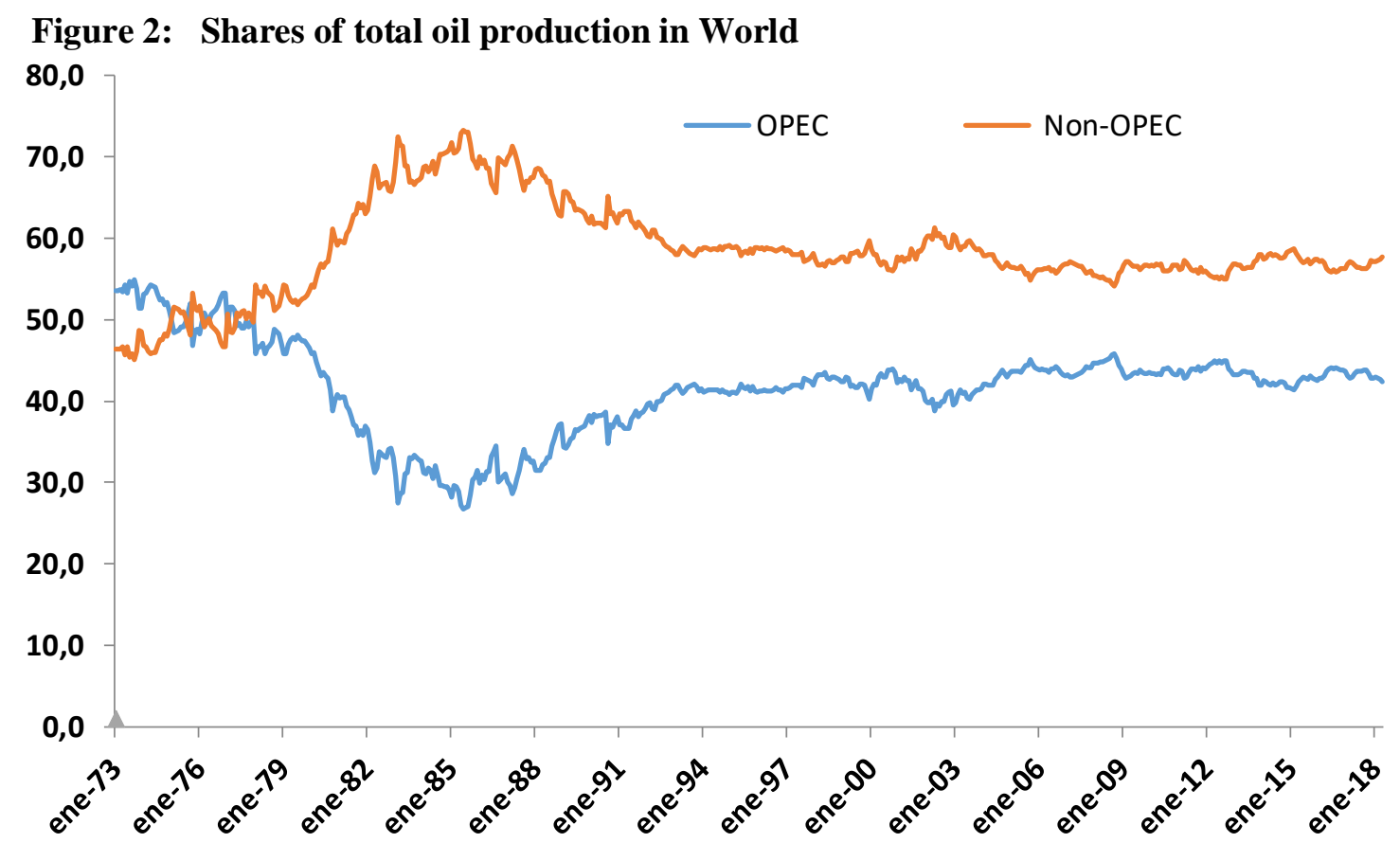

According to BP statistics (2018), OPEC has 1218.8 billion barrels of proven crude oil reserves, equivalent to $71.8 \%$ of the world's reserves. The total non-OPEC proven reserves is 4.777 billion barrels, equivalent to $28.2 \%$ of the world's total reserves. These statistics indicate that OPEC's stockpiles are much longer than non-OPEC reserves.

Due to lack of having long-term strategy to balance the price and production and maximizing the price against production as well as implementing passive policies, OPEC countries provide an opportunity for non-OPEC countries. This issue allows non-OPEC countries to participate as strong contributors in the production and export activities in global oil market. Remarkably, this role began in the late 1970s and peaked in the mid-1980s, which caused non-OPEC countries to be considered as an undeniable competitors against the OPEC organization.

Figure 3 shows the share of proven world oil reserves in terms of OPEC and non-OPEC groups in 1973-2017. According to related estimations, the OPEC share at the end of 2017 is about $71.8 \%$ of the world's total reserves, indicating a huge difference in oil resources with non-OPEC 
countries. That is why OPEC countries have been affected by political developments due to the highest levels of world oil reserves. The effect of these developments has been very influential on the issues of oil production, supply and prices in the world market.

Figure 3: World proven crude oil reserves by OPEC and Non-OPEC (percentage)

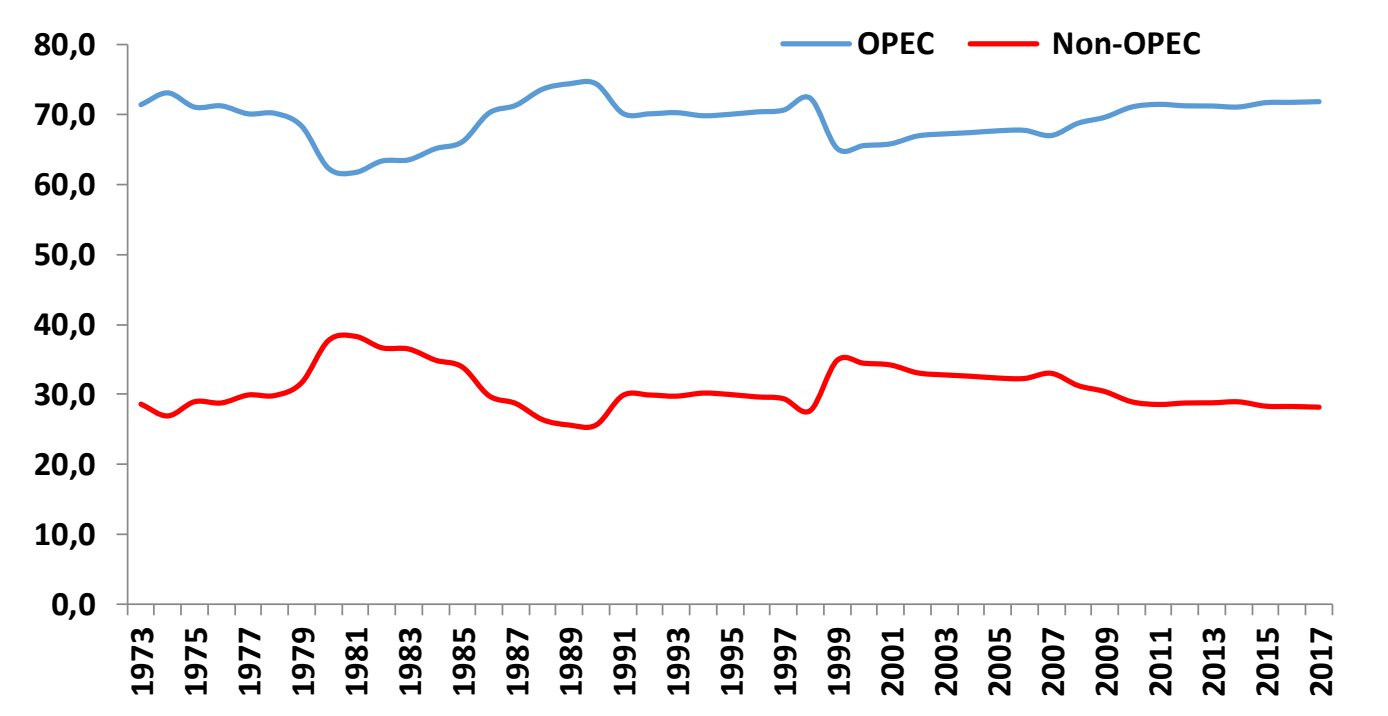

In light of the influences on OPEC's and non-OPEC oil production, understanding the time series behavior of OPEC, non-OPEC and total (world) oil production is critical in the assessment of the impact of oil shocks and structural breaks on both oil supply and the repercussions for global economic activity. This study examines the degree of persistence, potential breaks and outliers of oil production for OPEC non-OPEC and world within a fractional integration modelling framework. In particular, two important features commonly observed in oil production data are the persistence across time and breaks in production. The order of integration of energy variables is important because it figures out whether shocks to energy production have permanent or temporary effects. Also, determining whether shocks to oil production are transitory or persistent is relevant 
in the formulation of energy-related policy as well as stabilization policies (Smyth, 2013, Barros et al, 2011, Barros et al, 2016).

///In this paper we focus on the statistical aspects of the oil production in OPEC, non-OPEC and world, investigating, for instance, if this variable is mean reverting or not, i.e., if the effect of the shocks has a transitory or a permanent nature. For this purpose, we employ techniques which are based on fractional integration. By using this methodology, we allow for a higher degree of flexibility in the dynamic specification of the series compared with the classical methods that are exclusively based on integer degrees of differentiation. In other words, allowing the degree of differentiation to be real, we permit for fractional values and thus the standard cases of stationary $\mathrm{I}(0)$ and non-stationary $\mathrm{I}(1)$ appear as particular cases of interest when the differencing parameter, $\mathrm{d}$, is 0 or 1 respectively. However, we can consider additional cases, including stationary long memory models $(0<\mathrm{d}<0.5)$; non-stationary though mean reverting $(0.5 \leq \mathrm{d}<1)$, and nonstationary explosive behavior $(\mathrm{d}>1)$. The paper is structured as follows: Section 2 reviews some previous works of the oil production, Section 3 describes the methodology, Section 4 presents the data and the main empirical results, and Section 5 concludes the paper.

\section{Some empirical studies}

Different studies have been done on oil and other energy sources of production. These studies are divided into two categories; those which have used unit root tests for stationary hypothesis and a few studies which have used Fractional integration method. In this section, we briefly review some of these studies. Using Dickey Fuller and Phillips-Peron tests, Hutchison (1994) tested the presence of a unit root in energy production variables for three countries (Norway, the Netherlands and the United Kingdom). His results indicated that the unit root hypothesis for model variables 
including oil production cannot be rejected and the data are considered as first difference data with integrated order 1 or I (1). Kaufmann and Cleveland (2001) studied the effect of political, economic and geological factors on crude oil production in the 48 states of the US in the period 1938 to 1991 using the unit root test, Augmented Dickey Fuller and vector error correction model. Their results showed that the unit root hypothesis for model variables can't be rejected and the data are considered as integrative order 1 or I (1). Gil Alana and Candelon (2004) conducted a study on the industrial production indexes (IPI) in four Latin American countries (Brazil, Argentina, Colombia and Mexico) by the use of fractional integration method. Their results showed that the degrees of fractional integration affect the results of classical unit-root tests. Also, the time series of industrial production for Argentina and Brazil were between zero and 0.5, which is a reason for the presence of seasonal long memory indicating that the effects of any shock is persistent for a long period. Narayan et al (2008) investigated the unit root properties of crude oil and NGL production for 60 countries for the period 1971-2003. The selected countries were divided into 7 smaller panels; 18 OECD countries, 10 Latin American countries, four Central and Eastern European countries, nine African countries, 10 Middle Eastern countries and nine Asian countries. They concluded that the unit-root hypothesis is rejected for some country groups. In other words, the data on crude oil and NGL production are jointly stationary. Maslyuk and Smyth (2009) investigated the crude oil production of 17 OPEC and non-OPEC countries using data from 1973 to 2007 by a non-linear approach. The results of their study revealed that a unit root in both regimes is present for 11 countries; for 2 countries there is a partial unit root in the first regime and for 4 countries a partial unit root is present in the second regime. Using fractional integration modelling framework, Barros et al. (2011) studied the time series of crude oil production for OPEC member countries by monthly data from January 1973 to October 2008. The results showed that 
in 10 out of the 13 countries there was mean reverting persistence in oil production with breaks identified. In addition, shocks affected the structure of OPEC oil production and consequently they would have persistent effects on all of these countries in the long-run. Furthermore, there was no structural break in the oil production data of 4 countries (Algeria, Angola, Indonesia, and Kuwait), but there were two breaks for Iraq and Saudi Arabia and one single break was observed in other countries.

Maslyuk and Dharmaratna (2012) studied the time series behavior of coal production and their export using unit root for Australia during the period from 1966 to 2009. They concluded that coal production was non-stationary. Ratti and Vespignani (2015) investigated oil price and oil production behavior of OPEC and non-OPEC countries using 1974: Q1-2012: Q4 data. They used unit root tests: Kwiatkowski-Phillips-Schmidt-Shin (KPSS) and Augmented Dickey Fuller (ADF). Based on KPSS test, it was found that all variables were stationary, but they were first difference stationary according to ADF method. Barros et al (2016) studied the data on energy production (including oil production, natural gas production, LGN production, and refined oil) for Brazil over the period from January 2000 to February 2013 in a fractional integration method. Their results showed that the orders of integration in the series is smaller than 1 and thus implying mean reversion. Also, the time series for natural gas production and LGN production faced a structural break. Monge et al (2017) investigated the behavior of shale oil production and WTI prices in the United States by the use of fractional integration method for the period from 2000-01 to 2016-03. Their study results showed that high-frequency transmission and low-frequency transmission occurred in the period 2009-2003 and 2014-2009, respectively. Also, for the period 2014-2009 and the entire period the orders of integration is equal to or higher than 1 in all cases. 


\section{Methodology}

One characteristic of many economic and financial time series is its non-stationary nature. There exists a variety of models to describe such non-stationary behavior (Barros \& Gil-Alana, 2016). Until the 1980s a standard approach was to impose a deterministic (linear or quadratic) function of time, thus assuming that the residuals from the regression model were $\mathrm{I}(0)$ stationary. A few years later, and especially after the very influential work by Nelson and Plosser (1982), there was a general agreement that the non-stationary component of many aggregated series was stochastic rather than deterministic, and unit roots or first differences or I(1) processes, were commonly adopted. The I(1) case, however, is merely one particular model to describe such behavior. In fact, the number of differences required to render a series to be $I(0)$ may not necessarily be an integer value but any point in the real line. In such a case, the process is said to be fractionally integrated or $I(d)$. The $I(d)$ models belong to a wider class called long memory processes. We can provide two definitions of long memory, one in the time domain and other in the frequency domain.

Let us consider a zero-mean covariance stationary process $\left\{x_{t}, t=0, \pm 1, \ldots\right\}$ with autocovariance function $\gamma_{u}=E\left(x_{t} x_{t+u}\right)$. The time domain definition of long memory states that $\sum_{u=-\infty}^{\infty}\left|\gamma_{u}\right|=\infty$. Now, assuming that $x_{t}$ has an absolutely continuous spectral distribution, so that it has spectral density function:

$$
f(\lambda)=\frac{1}{2 \pi}\left(\gamma_{0}+2 \sum_{u=1}^{\infty} \gamma_{u} \cos (\lambda u)\right)
$$

The frequency domain definition of long memory states that the spectral density function is unbounded at some frequency in the interval $[0, \pi)$. For the purposes of the present study, we define an integrated of order 0 process or $\mathrm{I}(0)$ as a covariance stationary process with a spectral density 
function that is positive and finite at the zero frequency. In this context, $x_{t}$ is said to be $I(d)$ if it can be represented in the following form:

$$
(1-L)^{d} x_{t}=u_{t}, \quad t=0, \pm 1, \ldots,
$$

with $x_{t}=0$ for $t \leq 0$, where $L$ is the lag-operator $\left(L x_{t}=x_{t-1}\right)$ and $u_{t}$ is $I(0)$. The polynomial $(1-L)^{d}$ in (2) can be expressed in terms of its Binomial expansion, such that, for all real d,

$$
(1-L)^{d}=\sum_{j=0}^{\infty} \psi_{j} L^{j}=\sum_{j=0}^{\infty}\left(\begin{array}{l}
d \\
j
\end{array}\right)(-1)^{j} L^{j}=1-d L+\frac{d(d-1)}{2} L^{2}-\cdots
$$

and thus:

$$
(1-L)^{d} x_{t}=x_{t}-d x_{t-1}+\frac{d(d-1)}{2} x_{t-2}-\cdots
$$

In this context, $d$ plays a crucial role showing the degree of dependence in the time series. Thus, the higher the value of $d$ is, the higher the level of association will be between the observations. On the other hand, the above process also admits an infinite Moving Average (MA) representation. Thus, assuming that $u_{t}$ in (2) is a white noise process, the process can be expressed as

$$
x_{t}=\sum_{k=0}^{\infty} a_{k} u_{t-k}
$$

Where

$$
a_{k}=\frac{\Gamma(k+d)}{\Gamma(k+1) \Gamma(d)}
$$

and $\Gamma(x)$ represents the Gamma function. Thus, the impulse responses are also clearly affected by the magnitude of $d$, and the higher the value of $d$ is, the higher the responses will be.

Given the parameterisation in (1), several cases can be distinguished depending on the value of $d$. Specifically, if $d=0$, then, $x_{t}=u_{t}, x_{t}$ is said to be "short memory" or $I(0)$, and if the 
observations are auto-correlated they are of a "weakly" form (e.g., autoregressive), in the sense that they decay at an exponential rate; if $\mathrm{d}>0, \mathrm{x}_{\mathrm{t}}$ is said to be "long memory", or "strongly autocorrelated", because of the strong association between the values across time. If $\mathrm{d}$ belongs to the interval $(0,0.5) \mathrm{x}_{\mathrm{t}}$ is still covariance stationary, while $\mathrm{d} \geq 0.5$ implies non-stationary status. Finally, if $d<1$, the series is mean reverting in the sense that the effects of shocks disappear in the long run, contrary to what happens if $d \geq 1$ when they persist forever.We estimate $d$ using the Whittle function in the frequency domain (Dahlhaus, 1989) along with a testing procedure developed by Robinson (1994) that permits us to test the null hypothesis $H_{0}: d=d_{0}$ in (2) for any real value $\mathrm{d}_{0}$, where $x_{t}$ in (2) can be the errors in a regression model of form:

$$
y_{t}=\beta^{T} z_{t}+x_{t}, t=1,2, \ldots,
$$

where $y_{t}$ is the time series we observe; $\beta$ is a $(\mathrm{kx} 1)$ vector of unknown coefficients; and $z_{t}$ is a set of deterministic terms that might include an intercept (i.e., $z_{t}=1$ ), an intercept with a linear time trend $\left(z_{t}=(1, t)^{T}\right)$, or any other type of deterministic processes like dummy variables to examine the potential presence of outliers/breaks. The test statistic proposed in Robinson (1994) is based on the Lagrange Multiplier (LM) principle for testing $H_{0}: d=d_{0}$ in (2) and (3) is:

$$
\hat{r}=\frac{T^{1 / 2}}{\hat{\sigma}^{2}} \hat{A}^{-1 / 2} \hat{a},
$$

Where $\mathrm{T}$ is the sample size and:

$$
\begin{aligned}
& \hat{a}=\frac{-2 \pi}{T} \sum_{j=1}^{T-1} \psi\left(\lambda_{j}\right) g\left(\lambda_{j} ; \hat{\tau}\right)^{-1} I\left(\lambda_{j}\right) ; \quad \hat{\sigma}^{2}=\frac{2 \pi}{T} \sum_{j=1}^{T-1} g\left(\lambda_{j} ; \hat{\tau}\right)^{-1} I\left(\lambda_{j}\right) ; \\
& \hat{A}=\frac{2}{T}\left(\sum_{j=1}^{T-1} \psi\left(\lambda_{j}\right)^{2}-\sum_{j=1}^{T-1} \psi\left(\lambda_{j}\right) \mathcal{E}\left(\lambda_{j}\right)^{T} x\left(\sum_{j=1}^{T-1} \varepsilon\left(\lambda_{j}\right) \mathcal{\varepsilon}\left(\lambda_{j}\right)^{T}\right) x \sum_{j=1}^{T-1} \varepsilon\left(\lambda_{j}\right) \psi\left(\lambda_{j}\right)\right) \\
& \psi\left(\lambda_{j}\right)=\log \left|2 \sin \frac{\lambda_{j}}{2}\right| ; \hat{\varepsilon}\left(\lambda_{j}\right)=\frac{\partial}{\partial \tau} \log g\left(\lambda_{j} ; \hat{\tau}\right) ; \quad \lambda_{j}=\frac{2 \pi j}{T} ; \hat{\tau}=\operatorname{argmin}_{\tau \in T^{*}} \sigma^{2}(\tau),
\end{aligned}
$$


where $T^{*}$ is a compact subset of the $R^{q}$ Euclidean space. $I(\lambda j)$ is the periodogram of $u_{t}$ evaluated under the null, and $\mathrm{g}$ is a known function related to the spectral density function of $\mathrm{u}_{\mathrm{t}}$, i.e., $\mathrm{f}=$ $\left(\sigma^{2} / 2 \pi\right) g$. Thus, if $u_{t}$ is white, noise, $g=1$.

Though there exist many other procedures for estimating and testing the degree of differentiation in the series from a fractional viewpoint, we have decided to work with the above mentioned method (Robinson, 1994) because it has various advantages compared with other approaches. First, it has a standard null limit behavior, that is $(0,1)$ unlike what happens with most methods for testing for instance unit roots. Secondly, it allows us to incorporate deterministic terms and the limit distribution is not affected by these terms. Another advantage is that it is found to be the most efficient method in the Pitman sense against local departures. finally, and perhaps the most important one, is that the method remains valid for any real value of $\mathrm{d}$, including thus stationary $(\mathrm{d}<0.5)$ and non-stationary $(\mathrm{d} \geq 0.5)$ regions. Thus, we do not need to differentiate the series in case of non-stationary behavior. Lobato and Velasco (2007) proposed a similar testing method though based on the Wald test and thus it requires a consistent estimate of the differencing parameter, unlike the method employed here.

We also examine in this article the possibility of structural breaks, which are endogenously determined by the model. We follow here Gil-Alana (2008), which is basically an extension of Bai and Perron's (2003) approach to the fractional case. For simplicity, we describe first the case of a single break and consider a model of the form:

$$
y_{t}=\beta_{1}^{T} z_{t}+x_{t}, \quad(1-L)^{d_{1}} x_{t}=u_{t}, \quad t=1, \ldots, T_{b},
$$

And:

$$
y_{t}=\beta_{2}^{T} z_{t}+x_{t}, \quad(1-L)^{d_{2}} x_{t}=u_{t}, \quad t=T_{b}+1, \ldots, T,
$$


Where the $\beta$ 's are the coefficients corresponding to the deterministic terms; $d_{1}$ and $d_{2}$ may be real values; $u_{t}$ is $\mathrm{I}(0)$; and $T_{b}$ is the time of a break that is supposed to be unknown. The method is based on minimizing the residuals sum squares in the two subsamples and that can be easily extended to the case of two or more breaks. The model presented in (4) and (5) can also be written as:

$$
\begin{gathered}
(1-L)^{d_{1}} x_{t}=\beta_{1} \widetilde{z_{t}}\left(d_{1}\right)+u_{t}, t=1, \ldots, T_{b}, \\
(1-L)^{d_{2}} x_{t}=\beta_{2} \widetilde{z_{t}}\left(d_{2}\right)+u_{t}, t=T_{b}+1, \ldots, T,
\end{gathered}
$$

where $\overline{z_{t}}\left(d_{i}\right)=(1-L)^{d_{i}} z_{t}, i=1,2$. the procedure is based on the least square principle. First we choose a grid for the values of the fractionally differencing parameters $d_{1}$ and $d_{2}$, for example, $d_{i o}=0,0.01,0.02, \ldots, 1, i=1,2$. Then, for a given partition $\left\{T_{b}\right\}$ and given initial $d_{1}, d_{2}$ values, $\left(d_{10}^{(1)}, d_{2 o}^{(2)}\right)$, we estimate the $\square$ 's and the $\square$ 's by minimizing the sum of squared residuals,

$$
\begin{gathered}
\min \sum_{t=1}^{T_{b}}\left[(1-L)^{d_{1 o}^{(1)}} y_{t}-\beta_{1} \widetilde{z_{t}}\left(d_{1 o}^{(1)}\right)\right]^{2}+\sum_{i=T_{b}+1}^{T}\left[(1-L)^{d_{2 o}^{(1)} y_{t}-\beta_{2}} \widetilde{z_{t}}\left(d_{2 o}^{(1)}\right)\right]^{2} . \\
\text { w.r.t. }\left\{\alpha_{1}, \alpha_{2}, \beta_{1}, \beta_{2}\right\}
\end{gathered}
$$

$\operatorname{Let} \hat{\beta}\left(T_{b} ; d_{1 o}^{(1)}, d_{2 o}^{(1)}\right)$ denote the resulting estimates for partition $\left\{T_{b}\right\}$ and initial values $d_{1 o}^{(1)}$ and $d_{2 o}^{(1)}$. Substituting these estimated values on the objective function, we haveRSS $\left(T_{b} ; d_{1 o}^{(1)}, d_{2 o}^{(1)}\right)$, and minimizing this expression across all values of $d_{1 o}$ and $d_{2 o}$ in the grid we obtain $\left.R S S\left(T_{b}\right)=\operatorname{argmin}_{\{i, j\}} R S S, \mathrm{~d}_{10}^{(i)}, d_{2 o}^{(j)}\right)$. Next, the estimated break date $\widehat{T}_{k}$, is such that $\widehat{T}_{k}=$ $\operatorname{argmin}_{i=1, \ldots, m} R S S\left(T_{i}\right)$, where the minimization is taken over all partitions $T_{1}, T_{2}, \ldots, T_{i}$, such that $T_{i}-T_{i} \geq|\varepsilon T|$. Then, the regression parameter estimates are the associated least-squares estimates 
of the estimated k-partition, i.e., $\hat{\beta}_{i}=\hat{\beta}_{i}\left(\left\{\widehat{T}_{k}\right\}\right)$, and their corresponding differencing parameters, $\hat{d}_{i}=\hat{d}_{i}\left(\left\{\hat{T}_{k}\right\}\right)$, for $\mathrm{i}=1$ and 2 .

The model can be extended to the case of multiple breaks. Thus, we can consider the following model:

$$
y_{t}=\alpha_{j}+\beta_{j} t+X_{t}, \quad(1-L)^{d_{j}} X_{t}=u_{t}, \quad t=T_{j-1}+1, \ldots, T_{j}
$$

for $j=1, \ldots, m+1, T_{o}=0$ and $T_{m+1}=T$. Then, the parameter $\mathrm{m}$ is the number of changes. The break dates $\left(T_{1}, \ldots, T_{m}\right)$ are explicitly treated as unknown and for $i=1, \ldots, m$, we have $\lambda_{i}=T_{i} / T$, with $\lambda_{1}<\cdots<\lambda_{m}<1$. Following the same process as in the previous case, for each $j$ partition $\left(T_{1}, \ldots, T_{j}\right)$, denoted $\left\{T_{j}\right\}$, the associated least-squares estimates of $\alpha_{j}, \beta_{j}$ and the $d_{j}$ are obtained by minimizing the sum of squared residuals in the $d_{i}-$ differenced models, i.e.

$$
\sum_{j=1}^{m+1} \sum_{t=T_{j-1}+1}^{T_{j}}(1-L)^{d_{i}}\left(y_{t}-\alpha_{i}-\beta_{i} t\right)^{2}
$$

where $\hat{\alpha}_{i}\left(T_{j}\right), \hat{\beta}_{i}\left(T_{j}\right)$, and $\hat{d}\left(T_{j}\right)$ denote the resulting estimates. Substituting them in the new objective function and denoting the sum of squared residuals as $R S S_{T}\left(T_{1}, \ldots, T_{m}\right)$, the estimated break dates $\left(\widehat{T}_{1}, \widehat{T}_{2}, \ldots, \widehat{T}_{m}\right)$, are obtained $\operatorname{bymin}_{\left(T_{1}, T_{2}, \ldots T_{m}\right)} R S S_{T}\left(T_{1}, \ldots, T_{m}\right)$ where the minimization is again obtained over all partition $\left(T_{1}, \ldots, T_{m}\right)$. The above procedure requires the a priori determination of the number of breaks in the time series. Following standard procedures to select the number of breaks in the context of I(0) processes, Schwarz (1978) proposed the following criterion:

$$
\operatorname{SIC}(m)=\ln \left[R S S_{T}\left(\widehat{T}_{1}, \ldots, \widehat{T}_{m}\right) /(T-m)\right]+2 p^{*} \ln (T) / T
$$

Where $p^{*}$ is the number of unknown parameters. Yao (1988) used the Bayesian criterion:

$$
B I C(m)=\ln \left[R S S_{T}\left(\widehat{T}_{1}, \ldots, \widehat{T}_{m}\right) / T\right]+p^{*} \ln (T) / T
$$

Finally, Yao and Av (1989) proposed a third criterion based on 


$$
Y I C(m)=\ln \left[R S S_{T}\left(\widehat{T}_{1}, \ldots, \widehat{T}_{m}\right) / T\right]+m C_{T} / T .
$$

Where $C_{T}$ is any sequence satisfying $C_{T} T^{-2 d / k} \rightarrow \infty$ as $T \rightarrow \infty$ for some positive integerk.

The estimated number of break dates, $\widehat{m}$, is then obtained by minimizing the abovementioned information criteria given $M$ a fixed upper bound for $m$.

\section{Data and empirical results}

Monthly data of the oil production of OPEC and Non-OPEC were obtained from January 1973 to April 2018 from the Energy Information Administration (EIA, 2018). The data are seasonally adjusted. We observe in all cases a strong persistent pattern that is changing across time, suggesting the adoption of fractional integration with and without breaks. For each series we first consider the following model,

$$
y_{t}=\beta_{0}+\beta_{1} t+x_{t}, \quad(1-L)^{d} x_{t}=u_{t}, \quad t=1,2, \ldots
$$

where $y_{t}$ is the observed time series (in our case, the oil production in each case), $\beta_{0}$ and $\beta_{1}$ are the unknown coefficients corresponding to an intercept and a linear time trend; and $\mathrm{x}_{\mathrm{t}}$ is supposed to be integrated of order $d$ (or $I(d)$ ) implying thus that $u_{t}$ is $I(0)$. We report in Tables 1 and 2 the estimates of $\mathrm{d}$ for the three cases of no repressors, an intercept, and an intercept with a linear time trend, assuming that the errors are white noise (in Table 1) and auto-correlated (in Table 2). We marked in the tables in bold the most appropriate cases of each series according to the deterministic terms and report the estimates of $d$ along with their associated confidence intervals. These intervals were obtained as the values of $d$ where the null hypothesis could not be rejected at the $5 \%$ level with the tests of Robinson (1994).

Starting with the results based on white noise errors, in Table 1, we observe that for the world production, the time trend is required and the estimated value of $d$ is 0.84 . If we separate the 
production in OPEC and non-OPEC countries, the estimate is slightly higher (0.89) and the time trend is only required for the non-OPEC countries. In the three series, the confidence intervals exclude the case of $d=1$ implying mean reverting behavior (i.e., $d<1$ ) and transitory of the shocks.

Table 1: Estimates of $d$ under the assumption of no autocorrelation

\begin{tabular}{|l|lll|lll|l|l|}
\hline & \multicolumn{2}{|l|}{ No terms } & \multicolumn{2}{l|}{ An intercept } & \multicolumn{2}{l|}{ A linear time trend } \\
\hline World & 0.99 & $(0.93,1.05)$ & 0.85 & $(0.79,0.91)$ & $\mathbf{0 . 8 4}$ & $(\mathbf{0 . 7 8}, \mathbf{0 . 9 1})$ \\
\hline OPEC & 0.97 & $(0.91$, & $1.03)$ & $\mathbf{0 . 8 9}$ & $(\mathbf{0 . 8 4}, \mathbf{0 . 9 6})$ & 0.89 & $(0.84,0.96)$ \\
\hline Non- OPEC & 1.00 & $(0.95,1.07)$ & 0.88 & $(0.84,0.95)$ & $\mathbf{0 . 8 9}$ & $(\mathbf{0 . 8 5}, \mathbf{0 . 9 5})$ \\
\hline
\end{tabular}

Next we look, in Table 2, at the case of auto-correlated errors. The structure is the same as in Table 1. The results are qualitatively similar to those in Table 1, though there are also some differences. For example, the I(1) hypothesis cannot be rejected for the non-OPEC countries, and this hypothesis was rejected in favor of mean reversion with white noise errors. However, for the world and OPEC the results were consistent with those in Table 1, obtaining evidence of mean reversion, that is, with an estimated value of d significantly smaller than 1 .

Table 2: Estimates of $d$ under the assumption of autocorrelation

\begin{tabular}{|l|ll|lll|l|l|}
\hline & \multicolumn{2}{|l|}{ No terms } & \multicolumn{2}{l|}{ An intercept } & \multicolumn{2}{l|}{ A linear time trend } \\
\hline World & 0.96 & $(0.88,1.08)$ & 0.79 & $(0.72$, & $0.87)$ & $\mathbf{0 . 7 7}$ & $(\mathbf{0 . 7 0}, \mathbf{0 . 8 7})$ \\
\hline OPEC & 0.94 & $(0.86,1.06)$ & $\mathbf{0 . 8 7}$ & $(\mathbf{0 . 8 1}, \mathbf{0 . 9 6})$ & 0.87 & $(0.81,0.96)$ \\
\hline Non - OPEC & 1.00 & $(0.90,1.10)$ & 0.95 & $(0.88,1.05)$ & $\mathbf{0 . 9 6}$ & $(\mathbf{0 . 9 0}, \mathbf{1 . 0 5})$ \\
\hline
\end{tabular}

Table 3: Estimates of Break dates using Gil-Alana's (2008) methodology

\begin{tabular}{|l|l|l|}
\hline \multicolumn{1}{|c|}{ Series } & N. of breaks & \multicolumn{2}{c|}{ Break dates } \\
\hline Word & 5 & 1981M06, 1988M08, 1996M10, 2003M10, 2011M08 \\
\hline OPEC & 5 & 1981M06, 1988M09, 1995M07, 2004M06, 2011M08 \\
\hline Non - OPEC & 4 & 1979M10, 1986M07, 2000M11, 2011M08 \\
\hline
\end{tabular}


The number and time of production breaks of all three groups of OPEC, non-OPEC, and world countries were estimated endogenously using the approach proposed in Gil-Alana (2008), with a proposed $15 \%$ trimming of end-points, maximum of 5 breaks. Five breaks were found in the world and OPEC and four for the non-OPEC. The break dates are listed in Table 3. Very similar results, though only four breaks in all cases were obtained with Bai and Perron (2003). Accordingly, the production of OPEC, non-OPEC, and the world has been four structural breaks. Structural breaks caused by the Iran-Iraq war in the 1980s, the South East Asia crisis in the 1990s, and the Second World War in the Persian Gulf (US military strike against Iraq) in 2003 and the global financial crisis in 2007 onwards.

Table 4: Estimates of d for each subsample

\begin{tabular}{|c|c|c|c|c|c|c|}
\hline \multicolumn{7}{|c|}{ i) Uncorrelation (white noise) } \\
\hline & $1^{\text {st }}$ subs. & $2^{\text {nd }}$ subs. & $3^{\text {rd }}$ subs. & $4^{\text {rd }}$ subs. & $5^{\text {th }}$ subs. & $6^{\text {th }}$ subs. \\
\hline World & $\begin{array}{c}0.76 \\
(0.66,0.91)\end{array}$ & $\begin{array}{c}0.85 \\
(0.64,1.19)\end{array}$ & $\begin{array}{c}0.67 \\
(0.52,0.88)\end{array}$ & $\begin{array}{c}0.83 \\
(0.63,1.08)\end{array}$ & $\begin{array}{c}0.77 \\
(0.64,0.95)\end{array}$ & $\begin{array}{c}0.87 \\
(0.68,1.19)\end{array}$ \\
\hline OPEC & $\begin{array}{c}0.74 \\
(0.63,0.90)\end{array}$ & $\begin{array}{c}0.97 \\
(0.77,1.27)\end{array}$ & $\begin{array}{c}0.57 \\
(0.38,0.83)\end{array}$ & $\begin{array}{c}0.87 \\
(0.74,1.05)\end{array}$ & $\begin{array}{c}1.07 \\
(0.90,1.30)\end{array}$ & $\begin{array}{c}0.99 \\
(0.83,1.24)\end{array}$ \\
\hline Non - OPEC & $\begin{array}{c}0.82 \\
(0.73,0.94)\end{array}$ & $\begin{array}{c}0.55 \\
(0.42,0.71)\end{array}$ & $\begin{array}{c}0.83 \\
(0.76,0.92)\end{array}$ & $\begin{array}{c}0.68 \\
(0.57,0.84)\end{array}$ & $\begin{array}{c}1.07 \\
(0.83,1.40)\end{array}$ & --- \\
\hline \multicolumn{7}{|c|}{ ii) Autocorrelation (Bloomfield) } \\
\hline & $1^{\text {st }}$ subs. & $2^{\text {nd }}$ subs. & $3^{\text {rd }}$ subs. & $4^{\text {rd }}$ subs. & $5^{\text {th }}$ subs. & $6^{\text {th }}$ subs. \\
\hline World & $\begin{array}{c}0.74 \\
(0.58,1.02)\end{array}$ & $\begin{array}{c}0.17 \\
(-0.11,0.61)\end{array}$ & $\begin{array}{c}0.52 \\
(0.33,0.84)\end{array}$ & $\begin{array}{c}0.55 \\
(0.19,0.95)\end{array}$ & $\begin{array}{c}0.55 \\
(0.15,0.92)\end{array}$ & $\begin{array}{c}0.44 \\
(0.20,0.75)\end{array}$ \\
\hline OPEC & $\begin{array}{c}0.68 \\
(0.44,0.98)\end{array}$ & $\begin{array}{c}0.52 \\
(0.29,0.91)\end{array}$ & $\begin{array}{c}0.22 \\
(-0.11,0.67)\end{array}$ & $\begin{array}{c}0.72 \\
(0.51,1.01)\end{array}$ & $\begin{array}{c}0.79 \\
(0.29,1.25)\end{array}$ & $\begin{array}{c}0.75 \\
(0.59,1.08)\end{array}$ \\
\hline Non - OPEC & $\begin{array}{c}1.00 \\
(0.84,1.23)\end{array}$ & $\begin{array}{c}0.62 \\
(0.33,0.94)\end{array}$ & $\begin{array}{c}1.00 \\
(0.87,1.22)\end{array}$ & $\begin{array}{c}0.54 \\
(0.40,0.76)\end{array}$ & $\begin{array}{c}0.63 \\
(0.42,0.94)\end{array}$ & -- \\
\hline
\end{tabular}

In bold, evidence of I(1) behaviour at the $5 \%$ level.

Table 4 summarizes the results for each subsample for the two types of uncorrelated and auto-correlated errors. We observe that for the World Series we do not observe large differences 
across the estimates, with the values ranging between 0.67 and 0.87 with white noise errors, are slightly smaller with autocorrelation. For the OPEC, the most notorious feature is the evidence of mean reversion during the first subsamples but the lack of it during the last three. For the nonOPEC, mean reversion takes place in all cases under white noise errors and the I(1) hypothesis cannot be rejected in the three series under Bloomfield-type autocorrelation. Overall, we do not observe any systematic pattern in the behavior of $d$ implying that the values have been relatively stable across the subsamples.

\section{Concluding Remarks}

In this article we have examined the time series behavior of the world, OPEC and non-OPEC oil production, for the time period from January 1973 to April 2018, using fractionally integrated techniques. These methods are more general than the standard ones based on integer degrees of differentiation and include them as particular cases of interest. Moreover, the possibility of structural breaks still in the context of I(d) processes is also taken into account. The results indicate that mean reversion takes place in case of the world and OPEC production but not in case of the non-OPEC. Thus, in case of exogenous shocks affecting negatively oil production stronger measures must be adopted by the non-OPE countries. We also observe some evidence of multiple structural breaks in the three series though the degree of persistence seems to be relatively stable across the different subsamples. 


\section{References}

Bai, J. \& Perron, P. (2003). Computation and Analysis of Multiple Structural Change Models, Journal of Applied Econometrics, Vol.18, pp. 1-22.

Barros, C.P., \& Gil-Alana, L.A. (2016), Oil prices: Persistence and Breaks, Energy Sources, Part B. Economics, Planning and Policy 2,137-149.

Barros, C.P, Gil-Alana, L.A., \& Payne, J.E., (2011). An analysis of oil production by OPEC countries: persistence, breaks, and outliers. Energy Policy, 39, 442-453.

Barros, C.P., Gil-Alana, L.A, \& Wanke, P, (2016), Energy production in Brazil: Empirical facts based on persistence, seasonality and breaks, Energy Economics, 54: 88-95.

BP. (2018). BP Statistical Review of World Energy.

Caner, E. and Hansen, B.E. (2001), Threshold autoregression with a unit root, Econometrica 69, 1555-1596.

Dahlhaus, R. (1989). Efficient Parameter Estimation for Self-Similar Process. Annals of Statistics, 17, 1749-1766.

EIA (Energy Information Administration), (2018), http://www.eia.gov.

Gil-Alana, L.A. (2008). Fractional Integration and Structural Breaks at Unknown Periods of Time, Journal of Time Series Analysis, 29, 163-185.

Gil-Alana, L.A. \& B. Candelon (2004). Seasonal and Long Run Fractional Integration in the Industrial Production Index of Some Latin American Countries, Journal of Policy Modelling 26, 301.313.

Hutchison, M.M., (1994). Manufacturing sector resiliency to energy booms: empirical evidence from Norway, the Netherlands, and the United Kingdom. Oxford Economic Papers 46, 311329.

Kaufmann, R. K. \& C. J. Cleveland. (2001). Oil production in the lower 48 states: Economic, geological, and institutional determinants. The Energy Journal 22 (1), 27-49.

Lobato, C.N. \& Velasco, C. (2007), Efficient Wald test for fractional unit roots, Econometrica 75, 2, 575-589.

Maslyuk S, Smyth R. (2009), Non-linear unit root properties of crude oil production. Energy Economics, 31,109-18.

Monge, M., Gil-Alana, L. A., \& de Gracia, F. P. (2017). U.S. shale oil production and WTI prices behaviour. Energy, 141, 12-19. 
Narayan, P.K., Narayan, S. \& Russell. S, (2008). Are oil shocks permanent or temporary? Panel data evidence from crude oil and NGL production in 60 countries. Energy Economics, 30, 919-936.

Nelson, C.R. \& Plosser, C.I. (1982). Trends and Random Walks in Macroeconomic Time Series, Journal of Monetary Economics, 10, 139-162.

OPEC, (2018), Annual statistical Bulletin OPEC 2018. http://www.opec.org.

Ratti, R.A. \& Vespignani, J.L. (2015), OPEC and non-OPEC oil production and the global economy, Energy Economics, 50: 364-378.

Robinson, P.M. (1994). Efficient Tests of Nonstationary Hypotheses, Journal of the American Statistical Association, 89, 1420-1437.

Schwarz, G. (1978). Estimating the Dimension of a Model, Annals of Statistics, 6, 461-464.

Smyth, R. (2013) Are fluctuations in energy variables permanent or transitory? A survey of the literature on the integration properties of energy consumption and production, Applied Energy, 104, 371-8.

Yao, Y.C. (1988). Estimating the Number of Change Points via Schwarz' Criterion, Statistics and Probability Letters, 6, 181-189.

Yao, Y.C. \& Au, S.T. (1989). Least Squares Estimation of a Step Function, Sankhya, Ser. A, 51, 370-381. 